\title{
Influence of power and aerobic exercise training on haemostatic factors after coronary artery surgery
}

\author{
D Wosornu, W Allardyce, D Ballantyne, P Tansey
}

\begin{abstract}
Objectives-To determine the effects of aerobic and power exercise training on haemostatic factors after coronary artery surgery and to compare the effect of the two exercise programmes.
\end{abstract}

Design-A prospective randomised controlled study of six months aerobic and power exercise training in men after coronary artery surgery.

Setting-Exercise rehabilitation classes in a teaching hospital in Glasgow.

Patients-55 men within 12 months of coronary artery surgery recruited from surgical centres and medical clinics and asked to participate in the study.

Interventions-Assessments, including a treadmill test, measurements of haemoglobin, platelet, fibrinogen, factor VIIc, and fibrinopeptide $A$ concentrations, and packed cell volume, done at baseline, three months, and six months. Patients in the two exercise groups attended training sessions three times weekly for six months. Control patients had no formal exercise training but continued with their leisure time activities.

Main outcome measures-Exercise performance on a treadmill, haematology, and haemostatic factor assays at baseline, three months, and six months.

Results-In the aerobic trained group exercise performance increased significantly over baseline at three months (interval change 146.7, 95\% confidence interval $(95 \%$ CI) 52.5 to $240.9 \mathrm{~s}$, $\mathbf{p}=0.003$ ) and was maintained at six months (interval change $172 \cdot 1,95 \%$ CI 63.3 to $280.9 \mathrm{~s}, p=0.002$ ). In the power trained groups significant improvement in exercise performance was delayed until six months (interval change $99.9 \mathrm{~s}$, $95 \%$ CI 20.3 to 170.5 s, $p=0.01$ ). Exercise performance in the control did not change significantly. Haemoglobin, concentration, packed cell volume, and platelet counts did not change significantly at any time. Fibrinogen concentration was significantly lower in the aerobic group than the other two groups at three months $(2.96 \mathrm{~g} / \mathrm{dl}$ compared with $3.3 \mathrm{~g} / \mathrm{dl}$ and $3.87 \mathrm{~g} / \mathrm{dl}$ in the power and control groups, $p=0.01$ ). The power group had a lower fibrinogen concentration than the control group $(p=0.04)$. The lower fibrinogen concentration in the aerobic group was maintained at six months. There was a gradual rise in factor VIIc concentrations in the aerobic and control groups compared with a small fall in the power group. Fibrinopeptide A concentrations showed no consistent changes.

Conclusions-Aerobic exercise training after coronary artery surgery causes an early favourable change in treadmill performance and in fibrinogen concentrations, that is maintained with further training. Power exercise training causes delayed benefit in treadmill performance. It also causes a small fall in fibrinogen concentrations. These changes may be relevant in reducing cardiovascular morbidity from graft failure and occurrence of myocardial infarction after coronary artery surgery.

(Br Heart J 1992;68:181-6)

Fibrinogen and factor VII are independent risk factors for coronary artery disease and myocardial infarction. ${ }^{12}$ High fibrinopeptide A concentrations are found in patients with unstable angina and acute myocardial infarction. ${ }^{3-5}$ The effects of acute exercise on haemostasis have been studied in normal people and in patients with coronary artery disease, with varying results. These are enhanced fibrinolysis, ${ }^{67}$ increased platelet count and aggregation ${ }^{68}$ and potentiation of coagulation by increased concentrations of factor VIII. ${ }^{7910}$

By contrast with acute exercise, little attention has been paid to the effects of chronic exercise on coagulation factors. ${ }^{611}$

Coronary artery surgery relieves angina and in selected subgroups of patients, prolongs life but it has had no impact on subsequent myocardial infarction. ${ }^{12-14}$ Also graft failure remains problematical and can be caused by thrombosis and progressive atherosclerosis, ${ }^{15}$ both of which are influenced by haemostatic factors. Exercise training has been found to improve exercise capacity ${ }^{16-18}$ and quality of life $^{19} 20$ in patients after coronary artery surgery. Exercise reduces cardiovascular risk through mechanisms that are as yet unclear. Intense aerobic exercise has been shown to reduce total cholesterol concentration and to increase high density lipoprotein (HDL) concentrations $^{2122}$ and exercise training after myocardial infarction has resulted in favourable lipoprotein changes. ${ }^{23}$

It is possible that exercise training can increase the benefits of coronary artery surgery by effecting changes in cardiovascular risk factors that are not influenced directly by myocardial revascularisation. Such risk fac- 
tors would include lipoproteins, fibrinogen, and factor VIIc concentrations. Exercise training as widely used in cardiac rehabilitation is usually aerobic exercise using low resistance high repetition exercises involving the rhythmic movement of large muscle groups. Power exercise has been little studied in cardiac patients because of fears associated with isometric exercise (high intensity low repetition exercise such as weight lifting) and its deleterious effects on blood pressure and therefore afterload. Power exercise is not, however, strictly isometric in that it also involved repetitious movements of a moderate weight load, by large muscle groups, with consequent increases in peripheral blood flow, cardiac output, ventilation, and oxygen consumption. In published reports it has been used only in previously trained patients. ${ }^{24} 25$

There are few studies on exercise training in patients after coronary artery surgery alone. In most reports, such patients form part of a group of "cardiac patients" including those with angina and previous myocardial infarction. It has been reported, however, that patients after coronary artery surgery achieved as much functional improvement as the other cardiac patients studied simultaneously..$^{1826}$ Age and extent of revascularisation do not appear to influence exercise tolerance. ${ }^{27}$ Those who dropped out of rehabilitation had worse outcomes in terms of return to work, smoking, and hospital. ${ }^{28}$ In the PERFEXT study patients after coronary artery surgery accounted for a third of the group. The exercise trained patients showed similar haemodynamic benefits such as increased $\mathrm{Vo}_{2}$ max to those with other forms of coronary artery disease. ${ }^{29}{ }^{30}$ Exercise training has been shown to cause beneficial changes in lipoprotein concentrations after coronary artery surgery. ${ }^{31}$

The haemostatic system is assuming a prominent role in pathogenesis and progression of coronary artery disease. Fibrinogen concentrations are high among patients with coronary artery disease and smokers. ${ }^{12}$ Low factor VIIc concentrations are thought to protect against thrombotic events as high factor VII activity causes raised thrombin production. ${ }^{32}$ Fibrinopeptide $\mathrm{A}$ is a major breakdown product of thrombin and its concentrations reflect activity of the coagulation system.

We studied the effects of six months supervised graduated aerobic and power exercise training on exercise capacity, haematological, and haemostatic factors in 55 men within 12 months of coronary artery surgery. This was part of a larger study of exercise rehabilitation after coronary artery surgery.

\section{Patients and methods}

Fifty five men (mean age 58, range 32-70) within 12 months of coronary artery surgery (range six weeks to 12 months) were studied. Table 1 shows patients' characteristics at baseline. No significant differences were found between the groups. Assessments done at
Table 1 Patient characteristics at baseline

\begin{tabular}{lcll}
\hline & Control & Aerobic & Power \\
\hline No & 20 & 15 & 20 \\
Age (y) mean (SD) & $56(7)$ & $57(9)$ & $60(6)$ \\
No grafts (mean) & $3 \cdot 1$ & $2 \cdot 8$ & $3 \cdot 4$ \\
Drugs: & & & \\
$\quad$ Aspirin & 18 & 12 & 17 \\
$\quad$ Dipyridamole & 17 & 11 & 15 \\
$\quad$ Anti-ischaemia & 4 & 0 & 1 \\
$\quad$ Diuretic & 4 & 1 & 4 \\
$\quad$ ACE I & 0 & 1 & 0 \\
Previous MI & 8 & 7 & 12 \\
Current smokers & 2 & 2 & 1 \\
Previous smokers & 10 & 7 & 14 \\
Employed & 7 & 4 & 7 \\
Off work & 5 & 4 & 4 \\
Retired & 8 & 6 & 9 \\
Time since surgery (wk) & & & \\
$\quad$ median (range) & $12(8-28)$ & $12(6-36)$ & $12(6-44)$ \\
\hline
\end{tabular}

baseline, three months, and six months included a treadmill exercise test with modified Balke II protocol, body weight, skin fold thickness (biceps, triceps, scapular, and abdominal), haemoglobin, platelet, factor VIIc, fibrinogen, and fibrinopeptide A concentrations, and packed cell volume. Patients were recruited from a surgical centre and medical clinics and asked to participate in the study. Those unable to exercise on a treadmill or to attend exercise classes were excluded. After baseline assessment, patients were randomised to three groups: (1) control (no formal exercise training); (2) six months graduated supervised aerobic exercise training; (3) six months graduated supervised power exercise training. Informed consent was given by each patient and the study was approved by the local ethics committee.

\section{EXERCISE CLASSES}

Patients in both exercise groups attended exercise training sessions three times weekly in the same place supervised by a physiotherapist and a rehabilitation sister or a doctor. Each patient's session lasted from 12 to 60 minutes.

Aerobic exercises performed were modified from the Canadian Airforce PBX training programme. These were running on the spot, step ups, arm circling, star jumps, standing trunk curls, bridging, trunk rotation, side lying with hip abduction, arm raising, trunk side flexion, and crook lying with trunk rotation. The work performed was serially increased by increasing the number of repetitions of the exercises performed. Power exercises were based on weight training and Universal Multigym apparatus in which moderate weight loads are connected through a pulley system. Exercises performed were leg extensions, hamstrings curl, biceps curl, push down, pull down, press behind neck, bench press, pulley row, military press, and sit ups. The work performed was serially increased for each individual by increasing the weights and number of repetitions of each movement. There were rest periods of $45 \mathrm{~s}$ between each station. At the end of the training period each patient was exercising to his maximum. No heart rate or other cardiovascular monitoring was done during the exercises. Judgements regarding progression to the next stage of the programme were based on patient's performance and 
symptoms. Each patient ended the session with a ride on a stationary bicycle. Attendance records were kept.

\section{TREADMILL TESTS}

These were performed with a Marquette Case II system with modified Balke II protocol. This protocol consists of three minute stages. The speed and gradient are increased after the first stage from $3.2 \mathrm{~km} / \mathrm{h}$ gradient $0 \%$ to $4.8 \mathrm{~km} / \mathrm{h}$ gradient $4 \%$. The speed then stays constant while the gradient increases by $4 \%$ per stage until the 7th stage when the speed increases to $7 \cdot 2 \mathrm{~km} / \mathrm{h}$ gradient $20 \%$.

Two initial exercise tests were performed and the average of these was taken as the baseline exercise performance. Patients were familiar with the equipment, most of them having had exercise tests before their operation as part of their work up. We therefore considered that the treadmill test was a fair means of assessing exercise capacity in this group of patients. The exercise tests were symptom limited unless ventricular arrhythmias, or significant hypotension occurred. All treadmill tests were performed in the morning.

\section{BLOOD SAMPLES}

Samples of blood were taken through an indwelling cannula after an overnight fast. There had been no exercise training in the preceding 18 hours. The first $30 \mathrm{ml}$ was used for lipoprotein analysis; $5 \mathrm{ml}$ was used for measurement of haemoglobin, packed cell volume and platelets, $5 \mathrm{ml}$ for fibrinogen and factor VIIc concentrations, and $5 \mathrm{ml}$ for fibrinopeptide A assay.

\section{SAMPLE ANALYSES}

The technicians performing the assays were unaware of the patients' group. Samples were stored at $-85^{\circ} \mathrm{C}$ in plastic containers and tested in batches. Blood for factor VIIc and fibrinogen assays were stored for up to two weeks and fibrinopeptide A for up to six weeks. Haemoglobin concentration, packed cell volume, and platelet counts were measured automatically by Coulter counter.

\section{FACTOR VIIC ASSAY}

Factor VIIc was measured by the amount of correction of the one stage prothombin time found when patient's plasma is added to factor VII deficient plasma. The reagents required are available commercially and include factor VII deficient plasma, saline extract of brain, Owren's buffer, $\mathrm{pH} 7.35$, calcium chloride $0.025 \mathrm{~mol} / 1$, patient's citrated platelet poor plasma and reference plasma containing 100 IU/dl of factor VII. After preparing serial dilutions of the reference plasma in Owren's buffer, $0.1 \mathrm{ml}$ of factor VII deficient substrate plasma, $0.1 \mathrm{ml}$ normal plasma dilution and $0.1 \mathrm{ml}$ of saline extract of brain were placed into a glass test tube in a water bath at $37^{\circ} \mathrm{C}$. The mixture was incubated for $30 \mathrm{~s}$ and $0 \cdot 1 \mathrm{ml}$ of calcium chloride $(0.025 \mathrm{~mol} / \mathrm{l})$ is added. The clotting time was recorded. Each dilution was tested twice and the average clotting time was plotted on double log graph paper against calculated plasma factor VII concentration. The one in 10 dilution of normal plasma was considered to contain one unit of factor VII activity per $\mathrm{ml}(100 \mathrm{IU} / \mathrm{dl})$. The patient's plasma was similarly assayed, with dilutions tested depending on the expected factor VII concentrations. The clotting time of the dilution of patient's plasma was converted to factor VII activity by extrapolation from the standard graph. The normal range is $60-150 \mathrm{IU} / \mathrm{dl}$.

\section{FIBRINOGEN ASSAY}

The fibrinogen assay was carried out with a Multifibren kit (Behring) by a modification of the Clauss method. Multifibren consists of lyophilised $\alpha$-thrombin from bovine plasma. The principle is that citrated plasma is clotted by the addition of a relatively large amount of thrombin; clotting time depends mainly on the fibrinogen content of the blood sample. Plasma was diluted one in nine with barbital buffer solution ( $\mathrm{pH} 7 \cdot 6$ ) and the assay performed within 15 minutes: $0.2 \mathrm{ml}$ of citrated plasma solution and $0.2 \mathrm{ml}$ fibrintime were placed in a prewarmed test tube at $37^{\circ} \mathrm{C}$, incubated for $60 \mathrm{~s}$, and $0.2 \mathrm{ml}$ of Multifibren was added. The clotting time was recorded. The result was converted to $\mathrm{g} / \mathrm{dl}$ from a standard table of values supplied in the kit. Reference curves were checked with supplied control plasma (lyophilised human plasma). The normal range is $1 \cdot 8-3 \cdot 5 \mathrm{~g} / \mathrm{dl}$.

\section{STATISTICAL ANALYSES}

Results were considered on an intention to treat basis. All variables were analysed by analysis of variance and paired $t$ test for normal data, Wilcoxon signed rank test for non-normal data within groups, and unpaired $t$ test or MannWhitney $U$ test for differences between the groups. Results are expressed as mean (SEM or $95 \% \mathrm{CI}$ ). Where the data were non-normal, non-parametric methods for calculating confidence intervals were used.

\section{Results}

There were no exercise related deaths or cardiovascular events. Patients in the exercise groups attended $55 \%-65 \%$ of the sessions. Two patients dropped out of the power training group after a few weeks due to problems with their surgical scars.

Treadmill time and workload was significantly improved in the aerobic exercise trained groups at three months and the improvement was maintained at six months, whereas in the power group significant improvement in treadmill performance was delayed until six months. The control group did not show any significant change in treadmill performance (tables 2 and

Table 2 Treadmill times at each assessment (s) mean (SEM)

\begin{tabular}{llll}
\hline & Baseline & 3 months & 6 months \\
\hline Control & $699 \cdot 2(80.9)$ & $725.8(82.3)$ & $729.7(78.8)$ \\
Aerobic & $719.2(79 \cdot 2)$ & $865.9(72 \cdot 8)$ & $891.4(74 \cdot 4)$ \\
Power & $800.4(65.0)$ & $852.0(69.0)$ & $900.3(67.3)$ \\
\hline
\end{tabular}


Table 3 Interval change from baseline in treadmill times within the groups (s) mean (95\% CI)

\begin{tabular}{lrlrl}
\hline & 3 months & \multicolumn{3}{c}{6 months } \\
\hline Control & 26.6 & $(-10.8$ to 64.0$)$ & 30.6 & $(-34.9$ to 96.1$)$ \\
Aerobic & 146.7 & $(52.5$ to 240.9$)$ & 172.1 & $(63.3$ to 280.9$)$ \\
Power & 51.6 & $(-29.0$ to 132.2$)$ & 99.9 & $(20.3$ to 179.5$)$ \\
\hline
\end{tabular}

See text for $p$ values.

3). At three months, the interval change in performance between aerobic and power groups tended towards significance $(p=0.06)$, that between aerobic and control was significant $(p=0.005)$, and that between control and power was not $(p=0.28)$. At six months, the levels of significance for between group differences in performance were: aerobic $v$ control $\mathrm{p}=0.01$, power $v$ control $\mathrm{p}=0.08$, and aerobic $v$ power $\mathrm{p}=0 \cdot 14$. Haemoglobin, packed cell volume, platelet, or fibrinopeptide A concentrations, body weight, or mean skin fold thickness did not change significantly within or between groups at any time. Tables 4 and 5 show fibrinogen and factor VIIc concentrations. A significant fall in fibrinogen concentrations found in the aerobic trained group at three months $(p=0.01)$ was maintained at six months $(p=0.04)$ so that compared with the other two groups aerobic training had a favourable change in fibrinogen concentrations. (12\% reduction after six months; compared to $2 \%$ reduction in the power group and $4 \%$ reduction in the control group). The median value for interval change in fibrinogen concentrations in the control group at three months is $0.1 \mathrm{~g} / \mathrm{dl}$.

At six months, there was a fall in the fibrinogen concentration in the power and control groups to values lower than at baseline but the difference was not significant. Values for interval change in fibrinogen concentrations between the groups were: at three months aerobic $v$ control $\mathrm{p}=0.0004$, control $v$ power $\mathrm{p}=0.07$, aerobic $v$ power $\mathrm{p}=0.0002$, at six months aerobic $v$ control $\mathrm{p}=0.02$, control $v$ power $\mathrm{p}=0.09$, aerobic $v$ power $\mathrm{p}=0.05$. Factor VII concentrations rose with exercise training in the aerobic group but fell slightly in the power trained group so that at the end of six months the difference between the groups was statistically significant (power $v$ aerobic $\mathrm{p}=0.008$, power $v$ control $\mathrm{p}=0.06$ ).

\section{Discussion}

The rationale for this study was to investigate the ways in which exercise training may increase the benefits of coronary artery surgery.
Table 5 Factor VIIc concentrations (IU/dl) at each assessment (mean (SEM))

\begin{tabular}{|c|c|c|c|}
\hline & Baseline & 3 months & 6 months \\
\hline $\begin{array}{l}\text { Control } \\
\text { Aerobic } \\
\text { Power }\end{array}$ & $\begin{array}{ll}101.22 & (4 \cdot 31) \\
100 \cdot 4 & (6.73) \\
105.8 & (4.24)\end{array}$ & $\begin{array}{ll}107 \cdot 95 & (4 \cdot 5) \\
108 \cdot 2 & (6 \cdot 65) \\
107 & (4 \cdot 45)\end{array}$ & $\begin{array}{ll}109 \cdot 6 & (4.8) \\
113.67 & (5 \cdot 62) \\
104.4 & (3.39)^{\star}\end{array}$ \\
\hline
\end{tabular}

*Power $v$ aerobic $\mathrm{p}=0.008$ and power $v$ control $\mathrm{p}=0.06$

We compared aerobic exercise training with power exercise training in part to allay fears about power exercise training in cardiac patients and to directly compare the two types of exercise training in previously untrained patients after coronary artery surgery.

Fibrinogen and factor VII are independent risk factors for atherosclerosis and thrombosis. ${ }^{1}$ Exercise has been shown to protect against coronary artery disease both in primary ${ }^{33-35}$ and secondary prevention studies, ${ }^{36-38}$ although the mechanisms through which it exerts this influence are not clear. It does cause beneficial changes in lipoprotein profiles. ${ }^{21-23}$

Our preliminary results suggest a further mechanism by which chronic exercise is beneficial, specifically in men, after coronary artery surgery.

The study is one of effects and not mechanisms. A mechanism that has been suggested for the effects of exercise on haemostatic factors is that it reduces tissue hypoxia and lactic acid production after exercise due to improved cardiovascular performance with a reduced tendency to haemostasis. The tendency to increased membrane permeability and damage to muscle cells may also be reduced by exercise training ${ }^{6}$ with a reduction in the activation of coagulation.

Several studies have been carried out on the effects of acute and chronic exercise on the fibrinolytic system but only limited studies on the effects of chronic exercise on haemostatic factors. Williams et al showed that physical conditioning by 10 weeks of training on a treadmill augments the fibrinolytic response to thrombotic stimuli such as venous occlusion..$^{39}$ Regular vigorous sporting activities enhance blood fibrinolysis by reducing blood plasminogen activator inhibitor capacity in healthy men, but do not affect this significantly in patients after myocardial infarction in a rehabilitation class. ${ }^{40}$ This is by contrast with the findings of Estelles et al who showed that in patients after myocardial infarction in an exercise rehabilitation class, there was a slight improvement in fibrinolytic activity measured by plasminogen activator inhibitor activity compared with controls. ${ }^{41}$ Drygas reported on

Table 4 Fibrinogen concentrations at each assessment and changes from baseline within the groups (g/dl)

\begin{tabular}{|c|c|c|c|c|c|c|c|}
\hline \multirow[b]{3}{*}{$\begin{array}{l}\text { Control } \\
\text { Aerobic } \\
\text { Power }\end{array}$} & \multicolumn{3}{|c|}{ Fibrinogen concentrations at assessments (mean (SEM)) } & \multicolumn{4}{|c|}{ Interval changes from baseline (mean $(95 \% \mathrm{CI})$ ) } \\
\hline & Baseline & 3 months & 6 months & 3 month & & 6 month & \\
\hline & $\begin{array}{ll}3.48 & (0.22) \\
3.40 & (0.21) \\
3.18 & (0.12)\end{array}$ & $\begin{array}{ll}3.87 & (0.30) \\
2.96 & (0 \cdot 16)^{\star} \\
3.33 & (0 \cdot 13)\end{array}$ & $\begin{array}{ll}3.34 & (0 \cdot 19) \\
2.98 & (0 \cdot 16) \dagger \\
3 \cdot 12 & (0 \cdot 12)\end{array}$ & $\begin{array}{r}0.36 \\
-0.43 \\
0.15\end{array}$ & $\begin{array}{l}(-0.18,0.56) \\
(-0.63,-0.23) \ddagger \\
(-0.05,0.35)\end{array}$ & $\begin{array}{l}-0.15 \\
-0.41 \\
-0.06\end{array}$ & $\begin{array}{l}(-0.42,0 \cdot 12) \\
(-0.7,-0 \cdot 12) \S \\
(-0.26,0 \cdot 14)\end{array}$ \\
\hline
\end{tabular}

*Aerobic $v$ control $\mathrm{p}=0.01$ and aerobic $v$ power $\mathrm{p}=0.04$

†Aerobic $v$ control $\mathrm{p}=0.02$ and aerobic $v$ power $\mathrm{p}=0.08 ; \ddagger \mathrm{p}=0.01 ; \S \mathrm{p}=0.04$. 
changes in blood platelet function, coagulation, and fibrinolytic activity in response to varying degrees of acute exercise in 47 healthy men. He found that static exercise of short duration did not cause changes. Prolonged aerobic exercise consisting of 60 minutes on a bicycle ergometer caused strong activation of the fibrinolytic system and a slight increase in platelet count, but no change in platelet factor 4 , platelet aggregation ratio, recalcification, and prothrombin time. Repeated bouts of maximum exercise associated with acidosis caused a significant increase in platelet count, platelet factor 4 release, and strong intensification in fibrinolytic activity. ${ }^{42}$ Physical conditioning has been shown to enhance the fibrinolytic response to exercise in healthy men in a manner directly related to intensity of their activity. Thus marathon runners had increases in fibrinolytic activity of $76 \%$ with exercise compared with $63 \%$ for joggers and $55 \%$ for sedentary persons. They also found that packed cell volume, red cell count, platelets, and white cell count all increased significantly with exercise but like us, found no differences in resting packed cell volume resting red cell count, or red cell indices. $^{7}$

Acute exercise has not been shown to affect fibrinogen, factor V, factor VII or factor X concentrations. ${ }^{9}$ Factor VII concentrations have been shown to correlate positively with dietary fat $^{32}$ and with plasma cholesterol and triglyceride concentrations. ${ }^{43} \mathrm{We}$ did not give our patients specific dietary advice, and therefore are unable to exclude dietary variations as a factor in the difference in factor VIIc concentrations. Lipoprotein analyses are yet to be correlated with factor VIIc concentrations. The rise in factor VII concentrations among the aerobic trained group is disappointing. It could offset the benefits of low fibrinogen concentrations, but unlike that for fibrinogen, which is linear for non-fatal ischaemic heart disease, ${ }^{44}$ we do not know the exact relation between factor VII and cardiovascular risk. It is impossible to comment meaningfully on data we did not collect, that is influences of diet on factor VII concentrations in these men. Data are available on weight at entry and follow up (table 6). Body weight or mean skin fold thickness did not alter significantly in any of the groups during the period of assessment. Body weight would no more account for the changes in fibrinogen, lack of effect on factor VII, and improved treadmill performance than would smoking habit or drug history.

Fibrinogen concentrations are higher in smokers than in non-smokers, but this would not account for the differences we found in our patients. Fibrinogen may exert its effects on incidence of coronary artery disease through plasma viscosity or thrombogenesis. It is also a

Table 6 Body weight at each assessment (mean (SEM))

\begin{tabular}{|c|c|c|c|}
\hline & Baseline ( $\mathrm{kg}$ ) & 3 months ( $\mathrm{kg}$ ) & 6 months ( $\mathrm{kg}$ ) \\
\hline $\begin{array}{l}\text { Control } \\
\text { Aerobic } \\
\text { Power }\end{array}$ & $\begin{array}{l}71 \cdot 9(2 \cdot 4) \\
72 \cdot 8(2 \cdot 7) \\
72 \cdot 6(1 \cdot 6)\end{array}$ & $\begin{array}{l}73.0(2.5) \\
73.6(2 \cdot 7) \\
72.3(1.5)\end{array}$ & $\begin{array}{l}73 \cdot 4(2 \cdot 3) \\
74 \cdot 1(2 \cdot 8) \\
72 \cdot 7(1 \cdot 5)\end{array}$ \\
\hline
\end{tabular}

determinant of platelet behaviour. Concentrations within the physiological range have a noticeable and consistent effect on measures of the ability of platelets to aggregate, and also influence blood viscosity. ${ }^{324}$

Beneficial effects of power exercise training in this group were delayed. This would suggest that for immediate rehabilitation, aerobic exercise may be better. Most activities of daily living, however, involve a power componentfor example, gardening, DIY, and shopping so power training is a relevant part of rehabilitation programmes.

We did not study the effects of acute exercise on haemostatic factors either in training or on the treadmill. Several previous studies have considered the issue with variable results. We do not know what the effects antiplatelet or antiischaemic drugs have on haemostatic factors but our groups did not have significant differences in drug history.

It has been difficult to date to explain fully the beneficial effects of exercise on health. We often allude to other changes in behaviour of exercise trained subjects to account for these benefits. In our study, we have two exercise trained groups showing differences in both treadmill time and haemostatic factors despite attending sessions in the same place under supervision of the same persons and receiving the same treatment in all ways other than the type of exercise they performed. We cannot help but conclude (no matter what the precise mechanism is) that aerobic exercise training results in different and earlier benefits than power exercise training in these patients.

\section{LIMITATIONS OF THE STUDY}

Cardiopulmonary exercise testing could have improved the objectivity of the study with regard to exercise capacity. Unfortunately we did not have the necessary equipment. Motivation of patients plays a large part in exercise rehabilitation and its evaluation, and it is difficult to quantify the extent to which this is so without measures of maximum oxygen uptake and anaerobic threshold. Differences obtained, however, were sufficiently large between the exercise groups and controls to justify the use of treadmill exercise testing in the assessment of both types of exercise.

We did not measure plasma viscosity or other haemorrheological factors known to influence coronary artery disease although fibrinogen even in the physiological range, is known to affect platelet activity and plasma viscosity.

In summary, exercise training can increase the benefits of coronary artery surgery. Power training may be as effective as aerobic training and carries no special dangers but its benefits may be slower to start. Aerobic exercise training causes a significant fall in fibrinogen concentrations. Power training exerts a delayed and small beneficial influence on factor VII concentrations. The mechanisms of these influences and differences are worthy of further investigation.

It would be a matter of great speculation to try to predict the degree of reduction of risk of ischaemic heart disease achieved by the fall in 
fibrinogen concentration after aerobic exercise training. To find such a predictive factor, a larger and longer study than this would be needed. It is possible, however, to infer (from previous epidemiological studies) that a significant reduction in cardiac events can be expected from the fall in fibrinogen concentration achieved by our patients after aerobic exercise training. The results we have found await confirmation and long-term follow up of cardiovascular events in such a group of patients.

We thank Miss Elizabeth Lightbody for physiotherapy, Mis Rita Smith for her help with the exercise tests, the staff of the coagulation laboratory, and Mrs Margaret Stewart for preparing the typescript.

1 Meade TW, Mellows S, Brozovic M, et al. Haemostatic function and ischaemic heart disease: principal results of the Northwick Park Heart study. Lancet 1986;ii:533-7.

2 Wilhemsen L, Svardsudd K, Korsan-Bengsten K, Larsso $B$, Welin $L$, Tibblin G. Fibrinogen as a risk factor for stroke and myocardial infarction. N Engl J Med 1984;311 501-5.

3 Eisenberg PR, Sherman LA, Schectman K, Perez J, Sobel BE, Jaffe AS. Fibrinopeptide A: A marker of acute coronary thrombosis. Circulation 1985;71:912-8.

4 Theroux P, Latour JG, Leger-Gauthier C, De Lara J. Fibrinopeptide $A$ and platelet factor levels in unstable angina pectoris. Circulation 1987;75:156-62.

5 Wilensky RL, Zeller JA, Wish M, Tulchinsky M. Urinary fibrinopeptide A levels in ischaemic heart disease. $J \boldsymbol{A m}$ Coll Cardiol 1989;14:597-603.

6 Ferguson EW, Guest MM. Exercise, physical conditioning, blood coagulation and fibrinolysis. Thrombosis et Diasthesis Haemorrhagica 1974;31:63-71.

7 Ferguson EW, Bernier LL, Banta GR, Yu-Yahiro J, Schoomaker EB. Effects of exercise and conditioning on clotting and fibrinolytic activity in man. J Appl Physiol $1987 ; 62: 1416-21$

8 Sarajas MSS. Reaction patterns of blood platelets in exercise: characteristics, origin and possible coronary implications. Adv Cardiol 1976;18:176-95.

9 Iatridis SG, Ferguson JH. Effect of physical exercise on blood clotting and fibrinolysis. J Appl Physiol 1963;18: 337-44.

10 Davis GL, Abildgaard CF, Bernauer EM, Britton $M$ Fibrinolytic and haemostatic changes during and after maximal exercise in males. J Appl Physiol 1976;40: 287-92.

11 Sellier P, Corona P, Audouin P, Payen B, Plat F, Ourbak P. Influence of training on blood lipids and coagulation. Eur Heart $J 1988 ; 9$ (suppl $M$ ):32-6.

12 Alderman EL, Bourassa MG, Cohen LS, et al. Ten-year follow up of survival and myocardial infarction in the follow up of survival and myocardial infarction in the randomised Coro

13 Killip T. Twenty years of coronary bypass surgery. $N$ Engl J Med 1988;319:366-8.

14 Little WC, Guinn NS, Burrows MT, Kutcher MA, Kah FR, Applegate RJ. Cause of acute myocardial infarction late after successful coronary artery bypass grafting. $\mathrm{Am} J$ Cardiol 1990;65:808-10

15 Solymoss BC, Nadeau P, Millette D, Ing B, Campeau L. Late thrombosis of saphenous vein coronary bypass grafts related to risk factors. Circulation 1988;78(suppl I): I-140-3.

16 Hedback BEL, Perk J, Engvall J, Areskog N-H. Cardiac rehabilitation after coronary artery bypass graft: effects on exercise performance and risk factors. Arch Phys Med Rehabil 1990;71:2069-73.

17 Oldridge MB, Nagle FJ, Balk B. Aortocoronary bypass surgery: effects of surgery and 32 months of physical
conditioning on treadmill performance. Arch Phys Med Rehabil 1978;59:268-76.

18 Hartung GH, Rangel R. Exercise training in post myocardia infarction patients: comparison of results with high risk infarction patients: comparison of results with high risk coronary and post
19 Soloff PH. Medically and surgically treated coronary patients in cardiovascular rehabilitation: A comparative study. Int J Psychiatry Med 1980;9:93-106.

20 Hoad NA, Crawford IC. Rehabilitation after coronary artery bypass graft and improved quality of life. $\mathrm{Br} J$ Sports $\mathrm{Med}$ 1990;24:120-2.

21 Hartung GH, Squires WG, Gotto AM. Effect of exercise training on plasma HDL cholesterol in coronary disease patients. Am Heart J 1981;101:181-4.

22 Heath GW, Ehsani AA, Hagberg JM, Hinderlater JM, Goldberg AP. Exercise training improves lipoprotein lipid profiles in patients with coronary artery disease. $A m$ Heart J 1983;105:889-95.

23 Ballantyne FC, Clark RS, Simpson HS, Ballantyne D. The effect of moderate physical exercise on the plasma lipoprotein subfractions of male survivors of myocardia infarction. Circulation 1982;65:913-8.

24 Ghilarducci LE, Holly RG, Amsterdam EA. Effects of high resistance training in coronary artery disease. $\mathrm{Am}$ Cardiol 1989;64:866-70.

25 Keleman MH, Steward RT, Gillilan AW, et al. Circuit weight training

26 Horgan JH, Teo KK, Murren KM, et al. The response to exercise training and vocational counselling in post myocardial infarction and coronary artery bypass surgery patients. Ir Med J 1980;74:463-9.

27 Dornan J, Rolko A, Greenfield C. Factors affecting rehabilitation following aortocoronary bypass procedures. $\mathrm{Can}$ J Surg 1982;25:677-80.

28 Waites TF, Watt EW, Fletcher GF. Comparative functional and physiological status of active and dropout coronary bypass patients of a rehabilitation programme. $\mathrm{Am}$ Cardiol 1983;51:1087-90.

29 Froelicher P, Jensen D, Sullivan M. A randomised trial of the efficacy of exercise training after coronary artery bypass surgery. Arch Intern Med 1985;145:689-92.

30 Froelicher VF, Jensen D, Genter F, et al. A randomised trial of exercise training in patients with coronary heart disease. JAMA 1984;252:1291-7.

31 Agren B, Olin C, Castenfors J, Nisson-Ehle P. Improvements of the lipoprotein profile after coronary artery surgery: additional effects of an exercise training programme. Eur Heart J 1989;10:451-8.

32 Meade TW, Hypercoagulability and ischaemic heart disease. Blood Rev 1987;1:2-8.

33 Paffenberger RS, Hyde RT, Wing AC, Hsieh DC. Physical activity, all cause mortality and longevity of college activity, all cause mortality and longevi
alumni. N Engl J Med 1986;314:605-13.

34 Slattery ML, Jacobs DR, Nichaman MZ. Leisure time physical activity and coronary heart disease death. The US physical activity and coronary heart disease deat

35 Morris JN, Clayton DG, Everitt MG, Semmence AM Burgess EH. Exercise in leisure time: coronary attack and death rates. Br Heart $J$ 1990;63:325-34.

36 May GS, Eberlein KT, Furbery CD, Passamani ER DeMets DL. Secondary prevention after myocardia infarction: a review of long term trials. Prog Cardiovasc $D i s$ 1982;23:331-52.

37 Oldridge NB, Guyatt GH, Fischer MS, Rimm AA. Cardiac rehabilitation after myocardial infarction: combined experience of randomised clinical trials. JAMA 1988;260. 945-50.

38 O'Connor GT, Buring JE, Yusuf S, et al. An overview of randomized trials of rehabilitation with exercise after myocardial infarction. Circulation 1989;80:234-44.

39 Williams S, Logue EE, Lewis JL, et al. Physical conditioning augments the fibrinolytic response to venous occlusion ing augments the fibrinolytic response to venous occl

40 Speiser $\mathbb{W}$, Langer $W$, Pschaick $A$, et al. Increased blood fibrinolytic activity after physical exercise: comparative study in individuals with different sporting activities and in patients inter mith different sporting activities and in patients after myocardial infarction taking part in a rehabilitati.

41 Estelles A, Aznar J, Tormo G, Sapena P, Tormo V, Espana $F$. Influence of a rehabilitation sports programme on the fibrinolytic activity of patients after myocardial infarction. Thromb Res 1989;55:203-12.

42 Drygas W. Changes in blood platelet function, coagulation and fibrinolytic activity in response to moderate, exhaustive and prolonged exercise. Int J Sports Med 1988;9: 67-72.

43 Miller GJ, Walter SJ, Stirling Y, Thompson SG, Esnouf MP, Meade TW. Assay of factor VII activity by two techniques: evidence for increased conversion of VII to alpha VIIa in hyperlipidaemia with possible implications for ischaemic heart disease. $\mathrm{Br} J$ Haematol 1985;59: 249-58.

44 Meade TW, North WRS, Chakrabarti R, et al. Haemostatic function and cardiovascular death: early results of function and cardiovascular death: early 